\title{
EVALUATION OF TRIP GENERATION AT A FREE STANDING DISCOUNT SUPERSTORE
}

\author{
Mehrnaz Doustmohammadi ${ }^{1}$, Michael D. Anderson ${ }^{2}$, James J. Swain ${ }^{3}$ \\ ${ }_{1,3}^{3}$ Department of Industrial and System Engineering, University of Alabama in Huntsville, USA \\ ${ }^{2}$ Department of Civil and Environmental Engineering, University of Alabama in Huntsville, USA
}

Received 24 August 2015; accepted 17 February 2016

\begin{abstract}
Traffic impact analyses are necessary to predict traffic levels for new developments. The initial step, trip generation, determines the number of trips expected to enter and exit the facility after opening which is the basis for the remaining steps. This paper evaluates trips generation at a free standing discount superstore to determine, through statistical analysis, if the current design guides are accurate. The paper examines the traffic predicted and observed from a new development to determine the appropriateness of the trip generation rates. The paper concludes that the current rates are not accurately capturing the total traffic and are potentially leading to an under design of the infrastructure necessary to provide smooth traffic flow in the area post-development.
\end{abstract}

Keywords: trip generation, statistical analysis, free standing discount superstores.

\section{Introduction}

Traffic congestion has numerous negative effects, including lost productivity, environmental concerns and safety issues due to travel time delays, increases in air pollution and crashes. As new developments are constructed and opened, increases in traffic congestion in the proximity follow and require management to reduce the impact. Thus, the traffic impact analysis procedure evolved to identify and mitigate the impacts. The steps of the impact analysis involve trip generation, where trips to and from the development are identified; trip distribution, where the origin and destination of the trips are determined; and traffic assignment, where the trips are assigned to the roadway network (Edwards, 2015). The ability to accurately predict traffic volumes entering and exiting the new development is vital as the other steps in the process follow form this value.

This study determines whether the predictions for trip generation of a free standing discount superstore matched the actual trips observed, as recent studies have reported that free standing discount stores generate trips at a higher rate than published in the guidelines while other studies have indicated that the increases seen in recent years were an anomaly and the values in trip generation guides are correct (Vivian, 2006; Pearson, 2009; Guttenplan, 2012). This study examines the traffic entering and exiting a free standing discount superstore that was analyzed using a traffic impact analysis prior to construction using standard practice to the actual traffic entering and

${ }^{1}$ Corresponding author email: md0033@uah.edu 
exiting the location after construction to determine if the trip generation guidelines are statistically accurate.

Peak-hour traffic volume entering and exiting the free standing discount superstore were recorded on several dates to be compared to the predicted values from the original traffic impact analysis. For purposes of this work, the trip generation rates were taken from the ITE Trip Generation Manual, $8^{\text {th }}$ Edition that was the prevailing guide at the time of the traffic impact analysis (ITE, 2008). The statistical test included a hypothesis test to determine whether the mean peak-hour volume, $\mu$, entering and exiting the facility is similar to the predicted volume of the original study. Additionally, a comparison of trip generation rates from the updates to the ITE Trip Generation Manual, $9^{\text {th }}$ Edition is also performed to determine if the updates better reflect the actual traffic. This paper concludes that the number of trips predicted from current design guides under-predict the number of trips actually experienced after the free standing discount superstores are open.

\section{Literature Review}

Trip generation rates, truck trip generation rates and parking at stores have been a common area of study for the past 25 years. Several papers and reports have been written to address concerns over specific values that should be used for various types of shopping centers and stores (Cubukcu, 2001; Stiener, 1998; Johnson and Hammond, 2001; Goldner and Licinio, 2002; Ghezawi, 1998; Lullrell, 1991). Additionally, concerns over truck trip generation at stores and discounts stores have become a recent area of concern
(McCormick, 2010; Kawamura, 2005; Tadi, 1994; Brogan, 1979; Iding, 2002).

A review of recent literature indicates that there is concern about the accuracy of the trip rates for free standing discount stores that are used to support the traffic impact analysis and infrastructure design. The concern is that the popularity of these facilities has grown and the original traffic estimates which have remained constant for several decades are still relevant. Hensen studied different grocery stores and concluded that rates previous published varied greatly from actual values (Hensen, 1988). Vivian studied free standing discount superstores and concluded that the peak hour factor for these discount superstores should be closer to 5.5 trips per 1,000 square feet of floor area instead of 3.87 trips per square feet of floor area, which is the current factor in design guides (Vivian, 2006). Pearson conducted another study and concluded that the observed peak hour factor should be 4.50 trips per square feet of floor area instead of 3.87 trips per square feet of floor area (Pearson, 2009). Conversely, Guttenplan et al concluded that the spike in the peak hour factor for these free-standing discount superstores has passed and have now come back closer to the values seen in design guides (Guttenplan, 2012). This difference supported this effort to determine through data collection and statistical studies which result was appropriate.

\section{Data Collection}

The study performed to evaluate whether the traffic guidelines for free standing discount superstores match actual traffic after the opening of the store focused on an isolated 
development that open in summer 2014. The store was an ideal study location because this store was constructed as a stand-alone, without surrounding or add-on store that typically accompanies free standing discount superstores. The counts were taken in the winter/spring of 2015 to allow the traffic to not be influenced by the "newness" of the development and allow the volumes to represent typical levels.
There were three access points to the store that were counted to determine the actual number of trips entering and leaving the development. The data were collected on five weekdays using 15-minute intervals for both arrivals and departures during the PM peak-hour from 4.45 to 5.45. Tables 1 and 2 show the data collected for both arrivals and departures in 15 minute intervals.

Table 1

Survey Data for Arrivals

\begin{tabular}{|l|l|l|l|l|l|}
\hline Arrivals & 23-Feb & 9-Mar & 18-Mar & 30-Mar & 31-Mar \\
\hline $4.45-5$ & 67 & 82 & 95 & 108 & 115 \\
\hline $5-5.15$ & 105 & 101 & 102 & 94 & 94 \\
\hline $5.15-5.30$ & 87 & 124 & 95 & 99 & 90 \\
\hline $5.30-5.45$ & 106 & 108 & 90 & 101 & 75 \\
\hline & 365 & 415 & 382 & 402 & 374 \\
\hline
\end{tabular}

Table 2

Survey Data for Departures

\begin{tabular}{|l|l|l|l|l|l|}
\hline Departures & 23-Feb & 9-Mar & 18-Mar & 30-Mar & 31-Mar \\
\hline $\mathbf{4 . 4 5 - 5}$ & 71 & 90 & 95 & 105 & 111 \\
\hline $\mathbf{5 - 5 . 1 5}$ & 122 & 91 & 108 & 109 & 109 \\
\hline $\mathbf{5 . 1 5 - 5 . 3 0}$ & 118 & 124 & 122 & 125 & 120 \\
\hline $\mathbf{5 . 3 0 - 5 . 4 5}$ & 119 & 111 & 104 & 107 & 82 \\
\hline & 430 & 416 & 429 & 446 & 422 \\
\hline
\end{tabular}

\section{Statistical Analysis}

A variety of statistical tests were performed to study the difference between the actual traffic and predicted traffic.

\subsection{Regression Analysis}

Regression analysis was used to assess the presence or absence of correlation in the data collected for this study. The absence of correlation is necessary to ensure the data are not related, which would negate their use in subsequent tests, verify that the data are valid for estimating the variance.
The data were ordered to allow a Predecessor -Successor analysis to be performed using MINITAB Software. The data of each 15 -minute increments were plotted versus the next 15-minutes increment to examine if there is a relationship between the data, essentially, the hypothesis tested was to determine if the correlation was zero or not.

The scatter plots from the software are shown in figure 1 and 2 and the output from the software calculated p-value, which were larger than 0.05 . Therefore, it can be concluded that the data are not correlated. 


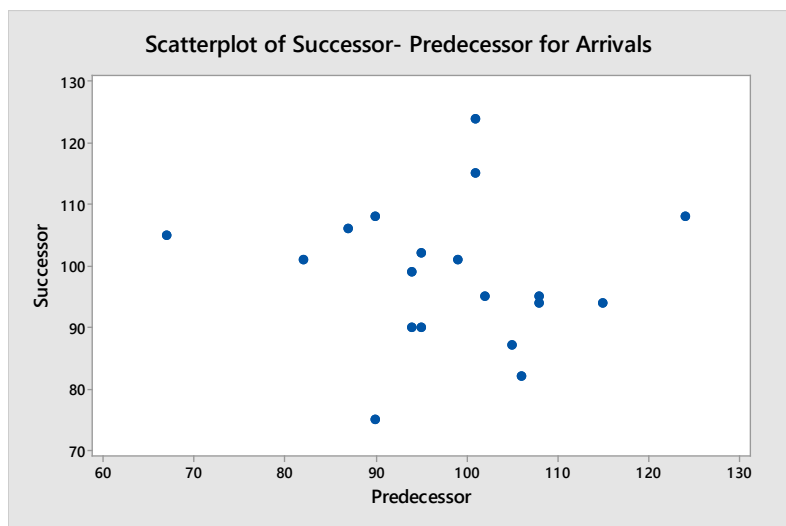

Fig. 1.

Predecessor - Successor Plot for Arrivals

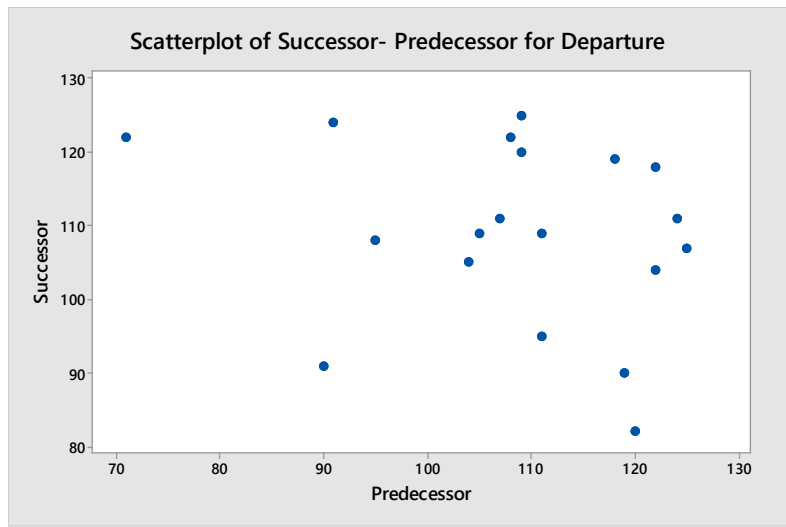

Fig. 2.

Predecessor - Successor Plot for Departures

\subsection{Normality}

The collected data, shown in Tables 3.1 and 3.2, were tested using MINITAB Software to assess the normality of the data. The test was performed by inputting the data of all of the 15-minute intervals. A normality hypothesis test used the null hypothesis $\left(\mathrm{H}_{0}\right)$ is that the data are normally distributed (Midas+, 2015). The normality test was performed for both sets of data, 15 minute intervals of arrivals and 15 minute intervals of departures. The test concludes a p-value is 0.781 and 0.105 for arrival and departures, respectively (see Tables 3 and 4); which are both greater than 0.05 , therefore, it was concluded that the two data sets were normally distributed. 
Table 3

Results of Normality test - Arrival

\begin{tabular}{|l|l|l|l|}
\hline Mean & Standard Deviation & N & P-Value \\
\hline 96.9 & 13.25 & 20 & 0.781 \\
\hline
\end{tabular}

Table 4

Results of Normality test - Departure

\begin{tabular}{|l|l|l|l|}
\hline Mean & Standard Deviation & N & P-Value \\
\hline 107.2 & 14.8 & 20 & 0.105 \\
\hline
\end{tabular}

The peak hour traffic volume is the sum of the two intervals, entering and exiting. Since the sum of two normal distributions is normal, the peak-hour traffic volume is also normal (Weisstein, 2015).

\subsection{Sample Size and Power Analysis}

To proceed to a hypothesis test, the sample size and power analysis was performed to determine if the five days of data collection provided enough statistical validity to base a test. Because the sample size was less than thirty, a t-distribution was used to verify if the sample size is sufficient. The analysis tested the difference between the mean of the traffic entering and exiting the development with the predicted number of cars. Analysis of sample size and power of the test were performed in MINITAB Software. The results, shown in Table 5 and 6 , show that the actual difference in mean for the arrivals, 45 vehicles, and that the actual difference in mean for the departures, 73 vehicles, can be tested at a level that exceed $90 \%$. This implies that the sample size is sufficient to perform the hypothesis to verify the difference in means.

Table 5

Power Analysis Results for Arrivals

\begin{tabular}{|l|l|}
\hline Difference & Power \\
\hline 21.121 & $60 \%$ \\
\hline 24.232 & $70 \%$ \\
\hline 27.903 & $80 \%$ \\
\hline 33.045 & $90 \%$ \\
\hline
\end{tabular}

Table 6

Power Analysis Results for Arrivals

\begin{tabular}{|l|l|}
\hline Difference & Power \\
\hline 11.587 & $60 \%$ \\
\hline 13.294 & $70 \%$ \\
\hline 15.308 & $80 \%$ \\
\hline 18.129 & $90 \%$ \\
\hline
\end{tabular}




\subsection{Hypothesis Test}

A statistical hypothesis test is used to examine an assumption that may or may not be true. A t-test was performed to verify whether the observed data differed significantly from the projected data of the traffic impact analysis. To run the test, the data used were taken from a random sample, the five unique days selected for data collection, and the data collected were normally distributed, as shown in a previous step.

For testing this particular analysis, the data was entered in MINITAB Software and the hypothesis test was run to determine if the mean number of cars arriving and departing in the peak hour differed from the predicted number. In this study, the predicted total vehicle arriving at the development for the PM peak hour was 342 vehicles. Tables 7 and 8 show the results for the t-test for the mean arrivals and departures, respectively. The P-value obtained from MINITAB Software was lower than the level of significance, which allow users to draw the conclusion that the mean is greater than 342 and the degree in which the P-value differs from the level of significance yields the result that the mean is significantly greater than 342 . In fact, it can be said with $90 \%$ confidence that the true mean of arrivals during a typical PM peak hour would be between 368 and 407 .

Table 7

1-Sample $t$ Test for the Mean of Arrivals

\begin{tabular}{|l|l|}
\hline Sample size & 5 \\
\hline Mean & 387.6 \\
\hline $\mathbf{9 0 \%}$ Confidence Interval & $(368.03,407.17)$ \\
\hline Standard Deviation & 20.526 \\
\hline Target & 342 \\
\hline P Value $=\mathbf{0 . 0 0 4}$ & \\
\hline
\end{tabular}

For PM peak-hour arrivals, the predicted total vehicles departing the development was for the PM peak hour was 355 vehicles. The P-value obtained from MINITAB Software was lower than the level of significance, which allow users to draw the conclusion that the mean is greater than 355 and the degree in which the P-value differs from the level of significance yields the result that the mean is significantly greater than 355 . In fact, it can be said with $90 \%$ confidence that the true mean of departure during a typical PM peak hour would be between 418 and 439.

Table 8

1-Sample t Test for the Mean of Departures

\begin{tabular}{|l|l|}
\hline Sample size & 5 \\
\hline Mean & 428.6 \\
\hline $90 \%$ Confidence Interval & $(417.86,439.34)$ \\
\hline Standard Deviation & 11.261 \\
\hline Target & 355 \\
\hline P Value $<0.0001$ & \\
\hline
\end{tabular}




\section{Results}

This study focused on the trip generation characteristics of a free standing discount superstore. Based on the observed traffic, the total traffic entering and exiting the location, on average, was 816 trips during the $\mathrm{PM}$ peak hour. Using the square footage of the development, 151,000 square feet, this leads to a value of 5.4 trips in the PM peak hour per every 1,000 square feet of developed area with a distribution of 47 percent entering the facility and 53 percent leaving the facility. As the statistics showed, this is significantly different than the 4.61 trips per square feet calculated from the design guide used for the traffic impact analysis and matches better with the result obtained from Vivian (Vivian, 2006).

When comparing the results with a recent update to the design guide, the values presented is 4.35 trips per square feet of floor area, the total number of trips expected during the PM peak hour is 657 (ITE, 2012). When comparing to the 816 trips observed on average, the increases in trips due to the change in the rate are still significantly lower than the actual total. This result indicates that the reducing of projected trips at free standing discount superstores, which was done recently, might not capture the actual traffic and the design guide should have potentially increased the factor.

Obviously, this is only one location and changing a design guide for a single location is not likely, it does lead to the notion that other studies should be considered at other locations to support or discount changes to the values. Additionally, the potential examination of regional influences on trip patterns might be necessary as free standing discount superstores might behave differently in different regions of the country/world.

\section{Conclusion}

This study examined actual traffic data counted entering and exiting a free standing discount superstore to statistically prove that the PM peak hour factor that has been suggested by design guides is not accurate and under predicts the number of vehicles that will be generated by the development. Several tests were performed in this research including: regression analysis for correlation, a normality test, sample size and power analysis and hypothesis test.

The implication of the under predicting of traffic volume in the trip generation step of a traffic impact analysis is problematic as the potential improvements necessary to ensure increases in traffic do not lead to unmanaged congestion. The ideal time for making infrastructure improvements to minimize the congestion issues is prior to construction of the development. Therefore, revisions to the design guides for trip generation for free standing discount superstores is recommended to ensure accurate traffic management.

\section{Reference}

Brogan, J. D.1979. Development of Truck TripGeneration Rates by Generalized Land-Use Categories, Transportation Research Record 716 (1979): 38-43.

Cubukcu, K. M. 2001. Factors Affecting Shopping Trip Generation Rates in Metropolitan Areas, Studies in Regional and Urban Planning 9 (2001): 51-68. 
Edwards, M. 2015. Traffic Impact Analysis: Community Guide to Development Impact Analysis. Available from Internet: <http://www.lic.wisc.edu/shapingdane/ facilitation/all_resources/impacts/analysis_traffic. htm >

Ghezawi, R. S.; Frederick J. W.; Chatterjee, A. 1998. Convenience Store Trip Generation, ITE Journal 5(1998): 1-4.

Goldner, L. G.; Da Silva Portugal, L. 2002. Trip Generation by Brazilian and Spanish Shopping Centres, International planning studies 7(3): 227-241.

Guttenplan, M.; Munroe, H.; Piszczatoski, A.; Smith, T.; Sokolow, G. 2012. Trip Generation Characteristics of Small Box Retail Stores, Major Single Retailer Distribution Centers, and Free-Standing Discount Superstores, ITE Journal 82(6): 36-40.

Hensen, R. 1988. Trip Generation Rates for Different Types of Grocery Stores, ITE journal 58(10): 21-22.

Iding, M.H.E.; Wilhelm, J. M.; Lóri, T. 2002. Freight Trip Generation by Firms. In Proceedings of the $42 \mathrm{nd}$ European Congress of the Regional Science Association, Dortmund. $14 \mathrm{p}$.

ITE (Institute of Transportation Engineers). 2008. Trip Generation Manual, 8th ed. 1919 p. ISBN-13:9781-933452-43-2.

ITE (Institute of Transportation Engineers). 2012. Trip Generation Manual, 9th ed. 2016 p. ISBN-13: 9781-933452-64-7

Johnson, K. L., Hammond, M.I. 2001. Trip-Generation Characteristics for Convenience Stores, ITE Journal $71(8): 26$.
Kawamura, K.; Shin, H.S.; McNeil, S.; Ogard, L. 2005. Business and Site Specific Trip Generation Methodology for Truck Trips. No. MRUTC 05-03. Midwest Regional University Transportation Center, College of Engineering, Department of Civil and Environmental Engineering, University of Wisconsin, Madison. 11 p.

Lullrell, G. 1991. Trip Generation Studies of Gas/ Convenience Stores, .ITE Journal 61(1): 34-37.

McCormack, E.; Bassok, A.; Ta, C.; Fishkin, E. 2010. Truck trip generation by grocery stores. University of Washington, Seattle, WA 98195, No. TNW2010-04. 45 p.

Midas+. 2015. Normal Probability Plot Interpretation. Available from Internet: <http://www.statit.com/ support/quality_practice_tips/normal_probability_ plot_interpre.shtml>.

Pearson, D. F.; Bochner, B. S.; Ellis, P.; Ojah, M. I. 2009. Discount Superstore Trip Generation, ITE Journal 79(6): 20-24.

Steiner, R. 1998. Trip Generation and Parking Requirements in Traditional Shopping Districts, Transportation Research Record: Journal of the Transportation Research Board 1(1617): 28-37.

Tadi, R. R.; Balbach, P. 1994. Truck Trip Generation Characteristics of Nonresidential Land Uses, ITE journal 64(7): 43-47.

Vivian, G. M. 2006. Trip Generation Characteristics of Free-Standing Discount Superstores, ITE Journal $76(8): 30-37$.

Weisstein, Eric W. 2015. Normal Sum Distribution. Available from Internet: <http://mathworld.wolfram. com/NormalSumDistribution.html $>$. 